\title{
JOURNAL.RU
}

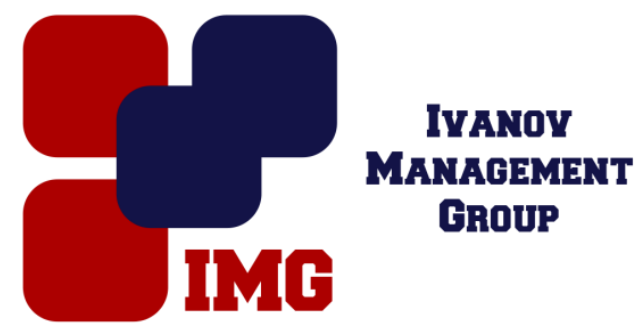

Руфкин А.В.

doi: 10.18411/lj-30-06-2017-25

idsp 000001:1j-30-06-2017-25

\section{Общий экономический анализ банка}

\section{Аннотация}

В данной статье дан краткий обзор общей экономической характеристики ПАО "МИнБанк" на сегодняшнем этапе. Проведён сравнительный анализ структуры активов и пассивов банка за 2015-2016 годы. Присвоена оценка деятельности коммерческой организации. Также рассмотрена управленческая структура и основные услуги, оказываемые банком в рамках расчётно-кассового обслуживания клиентов.

Ключевые слова: ПАО "МИнБанк", доля банка, структура активов, структура пассивов, удельный вес, управленческая структура, капитал.

Московский Индустриальный Банк был зарегистрирован в ноябре 1990 года Госбанком СССР на базе Московского городского управления Промстройбанка СССР в форме товарищества с ограниченной ответственностью. В 1997 году финансовый институт был преобразован в акционерный банк (сокращенное наименование - ОАО «МИнБ»). В августе 2015 года организационно-правовая форма банка была изменена на ПАО (сокращенное наименование -ПАО «МИнБанк»).

С 2000 года началось активное формирование филиально-офисной сети Банка в европейской части России. В настоящее время Банк представлен в 29 субъектах Российской Федерации. Банк России ежемесячно включает Банк в список 30-ти крупнейших российских кредитных организаций, а также относит его к кредитным организациям, признаваемым значимыми на рынке платежных 
услуг. Правительство Российской Федерации и Агентство по страхованию вкладов включило Банк в список 27 кредитных организаций, вошедших в программу докапитализации банков. Банк является участником Государственной программы поддержки предприятий малого и среднего бизнеса.

ПАО «МИнБ» является универсальным, многофилиальным и клиентоориентированным банком, оказывающий все виды банковских услуг как юридическим, так и физическим лицам, имея все необходимые лицензии на осуществление банковской деятельности и деятельности на рынке ценных бумаг. В настоящее время Банк обслуживает около 70 тысяч предприятий и организаций и свыше 1,5 млн. частных клиентов. Банк является участником Системы страхования вкладов и неоднократно привлекался Агентством по страхованию вкладов для выплат возмещения клиентам обанкротившихся банков. Рейтинговое агентство «Эксперт РА» шесть лет подряд ежегодно присваивает Банку рейтинг кредитоспособности на уровне «А» (высокий уровень кредитоспособности).

В соответствии с законодательством, Уставом и Положениями об органах управления Банка установлено распределение компетенций и полномочий между органами управления: Общим собранием акционеров Банка, Советом директоров, единоличным исполнительным органом (Президентом Банка) и Правлением Банка.

Общее собрание акционеров является высшим органом управления Банка, принимающим решения по основным вопросам его деятельности.

Акционеры Банка обладают правом на непосредственное участие в управлении Банком путем голосования по вопросам повестки дня общего собрания, принятия ключевых решений и утверждения документов, регулирующих систему корпоративного управления Банка, а также избрания членов Совета директоров, Президента, ревизионной комиссии Банка.

Совет директоров Банка является одним из важнейших элементов системы корпоративного управления ПАО «МИнБанк», осуществляющийстратегическое управление и общее руководство деятельностью Банка, включая системы управления рисками внутреннего контроля, а также контролирующий деятельность исполнительных органов. Совет директоров подотчетен общему собранию акционеров Банка.

Члены Совета директоров избираются общим собранием акционеров на срок до следующего годового собрания, и могут быть переизбраны 
неограниченное количество раз. Количественный состав Совета директоров в соответствии с Уставом Банка составляет семь человек.Председатель Совета директоровизбирается членами Совета директоров из их числа большинством голосов. Совет директоров Банкавправе в любое время переизбратьсвоего Председателя большинством голосов от общего числа членов Совета директоров.

Главной целью деятельности Банка является эффективное использование финансовых и кредитных ресурсов для получения прибыли.

Московский Индустриальный банк стабильно входит в тридцатку крупнейших банков России, определяемой Центральным Банком Российской Федерации по своей собственной методике расчетов (список составляется ежемесячно и публикуется на сайте Банка России и в Вестнике Банка России).

Московский Индустриальный банк является одним из крупных расчетных банков России. По экспертной оценке, платежи Банка через расчетную сеть Банка России составляют 10-15\% от всех объемов платежей по Орлу. Высокий уровень клиентского сервиса, отлаженные межбанковские технологии, конкурентные тарифы, квалифицированный персонал и индивидуальный подход к обслуживанию клиентов позволяют обеспечить первоклассное качество расчетно-кассового обслуживания клиентов. Передовые технологии, используемые Банком, позволяют предоставлять полный спектр услуг для своих клиентов по осуществлению расчетов в российских рублях и иностранной валюте. Широкая филиальная и корреспондентская сети дают возможность оперативного проведения платежей от плательщика к получателю за время, не превышающее 30 минут.

К основным услугам рассчетно-кассового обслуживания ПАО «МИнБанк» относятся:

- открытие и ведение счетов;

- осуществление расчетов;

- осуществление документарных операций (аккредитивы);

- оказание помощи в розыске не поступивших в пункт назначения денежных средств, а также платежных документов клиентов;

- оказание консультационных услуг по всем видам расчетов, по оформлению платежных документов и др.;

- оформление платежных документов;

- услуги по операциям с дорожными чеками. 
Московский Индустриальный банк оказывает полный спектр услуг в области кассового обслуживания Клиентов, включая:

- прием и пересчет наличных денежных средств;

- пересчет и зачисление на счет Клиента денежных средств не позднее следующего рабочего дня;

- выдачу наличных денежных средств по денежным чекам.

Для комфортного и безопасного дистанционного управления своими счетами ПАО «МИнБанк» предлагает клиентам Программно-Технический Комплекс «Интернет-Банк». Использование «Интернет-Банк» позволяет:

- осуществлять все расчеты непосредственно с рабочего места (из офиса, дома; не нужно устанавливать банковское программное обеспечение на свой компьютер);

- избежать ошибок в оформлении платежных документов - система уже при формировании документа выявляет ошибки при заполнении;

- существенно сократить расходы организации на расчётно-кассовое обслуживание;

- оптимизировать рабочее время сотрудников бухгалтерии;

- обеспечить максимально высокий уровень безопасности при обмене информацией с Банком;

- сократить транспортные расходы на поездки в Банк.

В целях обеспечения безопасности и сохранности денежных средств в ПАО «МИнБанк» применяются:

- самостоятельное изготовление Клиентом своих ключей электронной подписи;

- усиленная квалифицированная электронная подпись со сроком действия 3 года;

- шифрование канала между Банком и Клиентом;

- средства криптографической защиты информации и носители ключевой информации еToken ГОСТ;

- информирование Клиента о каждой совершенной операции с помощью SMS;

- устройства SafeTouch для визуализации платежных документов;

- AntiFraud система, помогающая выявить и предотвратить мошеннические операции. 
Доля Банка в активах-нетто в целом по банковской системе составила на 01.01.2017 года 0,32 \% (на 01.01.16 г. - 0,32\%).

По величине активов-нетто Банк находится на 37-м месте (на 01.01.2016 г. - 37-е место), сохранив свои позиции по сравнению с началом года.

По совокупным средствам корпоративных клиентов во всех валютах Банк на 01.01.2017 г. занимает 37-е место, поднявшись на три позиции по сравнению с началом года.

Доля Банка в капитале банковской системы составляет на отчетную дату 0,23\% (на 01.01.2016 г. - 0,35\%).

По размеру капитала Банк занимает 36-е место (на 01.01.2016 г. - 38-е место), поднявшись на две позиции по сравнению с началом года.

Доля в совокупных кредитах клиентам составляет 0,35 \% (на 01.01.2016 г. $-0,36 \%)$.

По объему кредитов клиентам Банк занимает на 01.01.17 г. 31-е место, потеряв одну позицию по сравнению с началом года.

Доля во вкладах физических лиц на 01.01.17 г. составляет 0,66 \% (на 01.01.2016 г. - 0,65\%).

По данному показателю Банк занимает 20-е место, поднявшись на одну позицию по сравнению с началом года. Данные показатели свидетельствуют о сохранении доверия к Банку со стороны частных инвесторов.

На основании данных бухгалтерской отчетности произведем анализ динамики статей актива баланса за 2 года: 2015-2016 гг., проанализируем его структуру (таблица 1).

Как видно из таблицы 1, по состоянию на 01.01.17 г. валюта баланса Банка составила в сумме 242 897,5 млн руб. и выросла за 2016 год на 17 464,2 млн рублей или 7,7 \% (в 2015-м году соответственно на 16 479,2 млн руб., или 7,9 $\%)$.

По-прежнему в структуре активов Банка наибольшуюдолю - 71,8 \% составляет чистая ссудная задолженность (на 01.01.16 г. - 73,5 \%),которая выросла за год на 8576 млн. руб., или 5,2 \%,и сложилась в сумме 174365,1 млн руб.(на 01.01.16 г. - 165 789,2 млн руб.).

Доля портфеля ценных бумаг в общем объеме активов Банка составляет на 01.01.17 г. 10,4 \%(на 01.01.16 г. - 10,1\%). 
Таблища 1

Сравнительный анализ структуры активов

ПАО «МИнБанк» за 2015-2016 годы, тыс. руб.

\begin{tabular}{|c|c|c|c|c|c|c|c|c|}
\hline \multirow[b]{2}{*}{$\begin{array}{c}\text { Наименование } \\
\text { статьи }\end{array}$} & \multirow[b]{2}{*}{01.01 .15 г. } & \multirow{2}{*}{$\begin{array}{c}\text { Удельн } \\
\text { ый вес, } \\
\%\end{array}$} & \multirow[b]{2}{*}{01.01 .16 г. } & \multirow{2}{*}{$\begin{array}{c}\text { Удельн } \\
\text { ый } \\
\text { вес, } \%\end{array}$} & \multirow{2}{*}{ 01.01.17 г. } & \multirow{2}{*}{$\begin{array}{c}\text { Удельн } \\
\text { ый } \\
\text { вес, } \%\end{array}$} & \multicolumn{2}{|c|}{ Изменение } \\
\hline & & & & & & & Абсолютное & Прирост, \% \\
\hline $\begin{array}{l}\text { Денежные } \\
\text { средства }\end{array}$ & 9081488 & 4,3 & 8534442 & 3,8 & 7923166 & 3,3 & -1158322 & $-12,8$ \\
\hline $\begin{array}{c}\text { Средства } \\
\text { кредитных } \\
\text { организаций в } \\
\text { Центральном } \\
\text { банке Российской } \\
\text { Федерации } \\
\end{array}$ & 9252688 & 4,4 & 9650851 & 4,3 & 7849228 & 3,2 & -1403460 & $-15,2$ \\
\hline $\begin{array}{c}\text { Обязательные } \\
\text { резервы }\end{array}$ & 1563199 & 0,7 & 3713708 & 1,6 & 3627533 & 1,5 & 2064334 & 132,1 \\
\hline $\begin{array}{c}\text { Средства в } \\
\text { кредитных } \\
\text { организациях }\end{array}$ & 1615361 & 0,8 & 1453507 & 0,6 & 3672030 & 1,5 & 2056669 & 127,3 \\
\hline $\begin{array}{c}\text { Финансовые } \\
\text { активы, } \\
\text { оценивамые по } \\
\text { справедливой } \\
\text { стоимости через } \\
\text { прибыль или } \\
\text { убыток } \\
\end{array}$ & 18419091 & 8,8 & 18424 & 0,0 & 21178 & 0,0 & -18397913 & $-99,9$ \\
\hline $\begin{array}{l}\text { Чистая ссудная } \\
\text { задолженность }\end{array}$ & 146869598 & 70,3 & 165789151 & 73,5 & 174365148 & 71,8 & 27495550 & 18,7 \\
\hline $\begin{array}{c}\text { Чистые вложения } \\
\text { в ценные бумаги } \\
\text { и другие } \\
\text { финансовые } \\
\text { активы, } \\
\text { имеющиеся в } \\
\text { наличии для } \\
\text { продажи }\end{array}$ & 3254031 & 1,6 & 6294954 & 2,8 & 8940210 & 3,7 & 5686179 & 174,7 \\
\hline $\begin{array}{c}\text { Чистые вложения } \\
\text { в ценные бумаги, } \\
\text { удерживаемые до } \\
\text { погашения }\end{array}$ & 1485367 & 0,7 & 16439775 & 7,3 & 16249019 & 6,7 & 14763652 & 993,9 \\
\hline \begin{tabular}{|c|} 
Основные \\
средства, \\
нематериальные \\
активы и \\
материальные \\
запасы \\
\end{tabular} & 8572614 & 4,1 & 3889907 & 1,7 & 5473561 & 2,3 & -3099053 & $-36,2$ \\
\hline Прочие активы & 10403882 & 5,0 & 13362319 & 5,9 & 18403972 & 7,6 & 8000090 & 76,9 \\
\hline $\begin{array}{c}\text { Всего } \\
\text { активов } \\
\end{array}$ & 208954120 & 100,0 & 225433330 & 100,0 & 242897612 & 100,0 & 33943492 & 16,2 \\
\hline
\end{tabular}

В таблице 2 представлен анализ пассивов банка. Общий объем привлеченных средств клиентовсоставляет на конец отчетного года 197865,6 млн руб.(на 01.01.16 г. - 166 778,7 млн руб.), или 81,5 \% валютыбаланса Банка 
(на 01.01.16 г. - 74 \%), и увеличилсяза год на 31 086,9 млн рублей или 18,6 \%(в 2015-м году соответственно на 10 214,6 млн руб.,или 6,5 \%).

Таблища 2

Сравнительный анализ структуры пассиваПАО «МИнБанк» за 2015-2016 годы, тысс. руб.

\begin{tabular}{|c|c|c|c|c|c|c|c|c|}
\hline \multirow[b]{2}{*}{$\begin{array}{c}\text { Наименование } \\
\text { статьи }\end{array}$} & \multirow[b]{2}{*}{01.01 .15 г. } & \multirow[b]{2}{*}{$\begin{array}{c}\text { Удельн } \\
\text { Ый вес, } \\
\%\end{array}$} & \multirow[b]{2}{*}{01.01 .16 г. } & \multirow[b]{2}{*}{$\left|\begin{array}{c}\text { Удельн } \\
\text { ый } \\
\text { вес, } \%\end{array}\right|$} & \multirow[b]{2}{*}{01.01 .17 г. } & \multirow[b]{2}{*}{$\left|\begin{array}{c}\text { Удельн } \\
\text { ый } \\
\text { вес, } \%\end{array}\right|$} & \multicolumn{2}{|c|}{ Изменение } \\
\hline & & & & & & & $\begin{array}{c}\text { Абсолютно } \\
\mathrm{e}\end{array}$ & $\begin{array}{c}\text { Прирост, } \\
\%\end{array}$ \\
\hline $\begin{array}{c}\text { Кредиты, } \\
\text { депозиты и } \\
\text { прочие средства } \\
\text { Центрального } \\
\text { банка Российской } \\
\text { Федерации } \\
\end{array}$ & 24306307 & 11,6 & 29897507 & 13,3 & 18708893 & 7,7 & -5597414 & $-23,0$ \\
\hline $\begin{array}{c}\text { Средства } \\
\text { кредитных } \\
\text { организаций } \\
\end{array}$ & 3604903 & 1,7 & 2754631 & 1,2 & 2285944 & 0,9 & -1318959 & $-36,6$ \\
\hline $\begin{array}{c}\text { Средства } \\
\text { клиентов, не } \\
\text { являющихся } \\
\text { кредитными } \\
\text { организациями } \\
\end{array}$ & 156564145 & 74,9 & 166778741 & 74,0 & 197865613 & 81,5 & 41301468 & 26,4 \\
\hline $\begin{array}{c}\text { Вклады } \\
\text { физических лиц }\end{array}$ & 102434576 & 49,0 & 119557522 & 53,0 & 150173016 & 61,8 & 47738440 & 46,6 \\
\hline $\begin{array}{c}\text { Финансовые } \\
\text { обязательства, } \\
\text { оцениваемые по } \\
\text { справедливой } \\
\text { стоимости через } \\
\text { прибыль или } \\
\text { убыток }\end{array}$ & 1529945 & 0,7 & 114457 & 0,1 & 51121 & 0,0 & -1478824 & $-96,7$ \\
\hline $\begin{array}{c}\text { Выпущенные } \\
\text { долговые } \\
\text { обязательства } \\
\end{array}$ & 616901 & 0,3 & 178064 & 0,1 & 3516185 & 1,4 & 2899284 & 470,0 \\
\hline $\begin{array}{c}\text { Прочие } \\
\text { обязательства } \\
\end{array}$ & 898849 & 0,4 & 2458571 & 1,1 & 3694013 & 1,5 & 2795164 & 311,0 \\
\hline $\begin{array}{c}\text { Резервы на } \\
\text { возможные } \\
\text { потери по } \\
\text { условным } \\
\text { обязательствам } \\
\text { кредитного } \\
\text { характера, прочим } \\
\text { возможным } \\
\text { потерям и } \\
\text { операциям с } \\
\text { резидентами } \\
\text { офшорных зон } \\
\end{array}$ & 163492 & 0,1 & 167479 & 0,1 & 389232 & 0,2 & 225740 & 138,1 \\
\hline $\begin{array}{c}\text { Всего } \\
\text { обязательств }\end{array}$ & 187684542 & 89,8 & 202349450 & 89,8 & 226511001 & 93,3 & 38826459 & 20,7 \\
\hline $\begin{array}{c}\text { Средства } \\
\text { акционеров }\end{array}$ & 1925003 & 0,9 & 2014288 & 0,9 & 2014288 & 0,8 & 89285 & 4,6 \\
\hline $\begin{array}{c}\text { Эмиссионный } \\
\text { доход }\end{array}$ & 5820029 & 2,8 & 6730736 & 3,0 & 6730736 & 2,8 & 910707 & 15,6 \\
\hline Резервный фонд & 265221 & 0,1 & 361640 & 0,2 & 439402 & 0,2 & 174181 & 65,7 \\
\hline
\end{tabular}




\begin{tabular}{|c|c|c|c|c|c|c|c|c|}
\hline $\begin{array}{c}\text { Переоценка } \\
\text { активов }\end{array}$ & 4735334 & 2,3 & 230995 & 0,1 & 296296 & 0,1 & -4439038 & $-93,7$ \\
\hline $\begin{array}{c}\text { Нераспределенная } \\
\text { прибыль прошлых } \\
\text { лет }\end{array}$ & 7559808 & 3,6 & 12968600 & 5,8 & 13672240 & 5,6 & 6112432 & 80,9 \\
\hline $\begin{array}{c}\text { Нераспределенная } \\
\text { прибыль за } \\
\text { отчетный год }\end{array}$ & 964183 & 0,5 & 777621 & 0,3 & -6766451 & $-2,8$ & -7730634 & $-801,8$ \\
\hline $\begin{array}{c}\text { Всего источников } \\
\text { собственных } \\
\text { средств }\end{array}$ & 21269578 & 10,2 & 23083880 & 10,2 & 16386511 & 6,7 & -4883067 & $-23,0$ \\
\hline Всего пассивов & 208954120 & 100,0 & 225433330 & 100,0 & 242897612 & $\begin{array}{c}100, \\
0\end{array}$ & 33943492 & 16,2 \\
\hline
\end{tabular}

Наибольший удельный вес в привлеченных ресурсахзанимают вклады населения $(60,6 \%)$, которыеувеличились за год на $25 \%$, что и явилось основнымдрайвером роста ресурсной базы Банка.

Капитал Банка по состоянию на 1 января 2017 года составил 16386511 тыс. рублей, уменьшившись за отчетный период на $23 \%$.

Анализ деятельности банка показал, что банк имеет устойчивое финансовое положение, однако наблюдается отрицательная динамика прибыли. Кроме того, несмотря на соответствие требуемым нормативам, ПАО «МИнБанк» подвержено риску возникновения убытков вследствие неспособности обеспечить исполнение своих обязательств в полном объеме и положенный срок в связи с ежедневной необходимостью использования имеющихся денежных средств для расчетов по счетам клиентов, при наступлении срока погашения депозитов, выдаче кредитов. Банк поддерживает базу финансирования, которая состоит в основном из средств, привлеченных за счет размещения долговых ценных бумаг и за счет привлечения срочных депозитов юридических и физических лиц.

Московский Индустриальный банк является одним из крупных расчетных банков России.Высокий уровень клиентского сервиса, отлаженные межбанковские технологии, конкурентные тарифы, квалифицированный персонал и индивидуальный подход к обслуживанию клиентов позволяют обеспечить первоклассное качество расчетно-кассового обслуживания клиентов. Передовые технологии, используемые Банком, позволяют предоставлять полный спектр услуг для своих клиентов по осуществлению расчетов в российских рублях и иностранной валюте.

Орловский филиал ПАО «МИнБанк» предлагает комплексное расчетнокассовое обслуживание корпоративных клиентов - резидентов и нерезидентов Российской Федерации в российских рублях и иностранной валюте.Орловский 
филиал ПАО «МИнБанк» предоставляет корпоративным клиентам возможность использования любого удобного вида телекоммуникационной связи (Telex, SWIFT, «Банк-Клиент» и других), что гарантирует высокую скорость и точность проведения расчетов.

В качестве рекомендаций по совершенствованию деятельности можно предложить Банку: современные концепции маркетинга финансовых услуг, в рамках которых реализовывать сопровождение новых и существующих банковских продуктов и услуг на всех стадиях их жизненных циклов; составление планов продаж банковских продуктов; разработку требований и методических материалов для модификации продуктовых предложений; внедрение современных технологий; развитие расчетно-информационных услуг, которые позволят привлечь на обслуживание и удержать в качестве своих клиентов крупные корпорации и холдинговые структуры.

\section{$* * *$}

1. Банковское дело: учебник [Текст]/под ред. Г. Н. Белоглазовой, Л. П. Кроливецкой. - 6-е изд., перераб. и доп.-М.: Финансы и статистика, 2016. -592 с.

2. Казимагомедов А. А. Банковское дело: организация и регулирование [Текст]: учеб. Пособие для студ. Учреждений высш. проф. образования/ А. А. Казимагомедов - М.: Издательский центр «Академия», 2015. - 239 с

3. Официальный сайт ПАО «МИнБанк» [Электронный ресурс]. - Режим доступа: http://www.minbank.ru.

4. Официальный сайт Банка России [Электронный ресурс]. - Режим доступа: http://www.cbr.ru.

5. Шестаков Р.Б. К вопросу об управлении социально-экономическими системами: теоретические основы и эволюция понятия // Регион: системы, экономика, управление. 2015. № 2 (29). С. 58-64. 